\title{
A moment in time
}

Published at cmaj.ca on May 29, 2009.

Space shuttle Endeavour's STS-118 mission was the 22nd shuttle flight to the International Space Station. During the 12-day mission in August 2007, the crew, including Canadian physician Dave Williams, continued construction on the space station.

$\mathrm{R}$ ight foot first. My strategy for getting into the foot restraint on the end of the space station's robotic arm, Canadarm2, always begins with my right foot. I feel my toes slide under the restraint and turn my heel outwards, locking the boot in place. The rest is easy. I slide my left foot in, release the handrails on the exterior of the space station, lean back and get ready for the ride of a lifetime.

Two hours have elapsed in the second spacewalk of our flight. Rick Mastracchio and I are removing and replacing a malfunctioning gyroscope, 1 of 4 aboard the space station that are critical to maintaining its orientation.

Since lifting off from Kennedy Space Center 4 days ago the Endeavour has orbited the earth more than 50 times to rendezvous and dock with the space station. Our crew of 7 trained for 2 years for this mission; each of our 4 spacewalks requires precision choreography between the spacewalkers and the crew inside operating the complex robotic arm. A single mistake can start a chain of catastrophic consequences.

The reassuring voice of pilot Charlie (Scorch) Hobaugh interrupts the quiet hum of the fan circulating oxygen in front of my face. He asks if I'm "ready for motion." Scorch is driving the arm that will carry me more than 30 metres from my position at the airlock to the shuttle's payload bay. "Ready for motion," I reply. I've said the words hundreds of times in training, but today is the first time I'll actually ride the famous station arm.

Controlled by our seasoned pilot, the arm starts to move. Our 350 kilomere altitude provides an astonishing view of Earth moving beneath us 25 times the speed of sound. We're travelling $8 \mathrm{~km}$ per second, faster than a bullet. Far below, whole continents drift by in minutes.

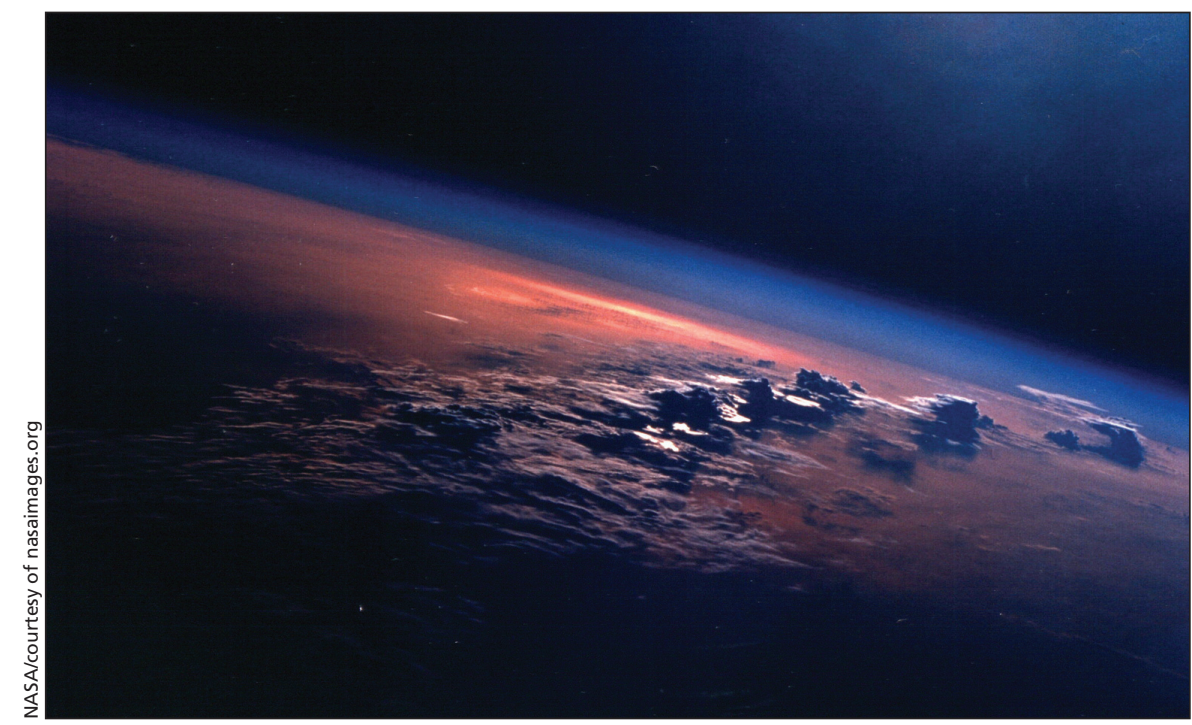

Years ago, in another millennium, during my medical studies at McGill University in Montréal, Quebec, I read poet Ted Rosenthal's book, How Could I Not Be Among You ? $^{1}$ chronicling his emotional response to the terminal phases of leukemia. For Rosenthal, the final phases of death provided profound insights. His value of living "in the moment," capturing forever the joy, wonder and beauty of each event in our lives has guided me for 3 decades. Standing alone on the slowly moving arm, suspended in space, I finally understood the significance of his words.

Turning slowly to my right, I look over the gleaming white shuttle into the infinite void of space. There is a blackness no earthly experience has prepared me for. There is nothing to be seen, no stars, no planets, just the vast unforgiving, cold, emptiness of space. To my left I see a fine latticework of clouds scattered over the Pacific. The sun is beginning to set, highlighting the thin turquoise layer of the Earth's atmosphere. Beneath me is home. Home to all of us struggling to live together in countries separated by borders that I cannot see. The entire history of all species including ours, has taken place on the blue sphere turning far below. I look back to my right at the infinity extending beyond our solar system, beyond known and unknown galaxies. I wonder if life exists or once existed somewhere in that vastness. In seconds that will stay with me a lifetime, I truly sense what it means to "live in the moment."

"Call the stop and let me know when you're ready to go to the worksite."
Scorch's call brings me back to the task at hand. As I ease toward the shuttle, the sound of my breathing blends with the quiet hum of the suit's fan. The significance of our mission is dwarfed by the magnitude of infinite space and cosmic time. It is an extremely humbling experience, yet I feel satisfied with the realization of the truth in Rosenthal's words that "whatever it is you have, you've already got. Right there. And it makes that moment an eternity." In one brief eternity, I felt embraced in the 4.5 billionyear history of our planet.

As the moon emerges above the port truss of the space station, the path to the lunar surface and on to Mars beckons, challenging future generations of space farers who will venture still farther within our solar system.

\section{Dave Williams MD \\ Professor of Surgery \\ McMaster University \\ Hamilton, Ont.}

Acknowledgements: The author thanks his friend and mentor Dr. Joe MacInnis for his helpful comments with this essay.

\section{REFERENCE}

1. Rosenthal T. How Could I Not Be Among You? New York (NY): Avon Publishing; 1975.

Dr. Williams, the first Canadian to be both an astronaut and aquanaut, holds the Canadian record for the total number of spacewalks and the most performed in a single mission. In 2008, he retired from the Canadian Space Agency. 